\title{
The Androgen Receptor in Castration-Resistant Prostate Cancer: Still a Clinical Opportunity?
}

\author{
Richard D. Finkelman ${ }^{1 *}$ and Glen Clack $^{2}$
}

${ }^{1}$ Senior Medical Director, Clinical Research, Oncology, AstraZeneca Pharmaceuticals LP, 1800 Concord Pike, P.O. Box 15437, Wilmington, DE 19850-5437, USA

${ }^{2}$ Medical Science Director, Global Medicines Development, AstraZeneca, Mereside, Alderley Park, Macclesfield, Cheshire SK10 4TG, UK

Keywords: Prostate cancer; Castration-resistant; Androgen; Receptor; Clinical trials

Prostate cancer is a leading cause of cancer death in men, with an estimate of about 241,000 new cases and 34,000 deaths due to prostate cancer in the United States in 2011 [1]. Prostate cancer is dependent on the androgen receptor (AR); the androgen axis shown to be a key driver of the disease [2]. This principle was first established more than 70 years ago by the demonstration that surgical castration will retard the progression of disease [3]. Prostate cancer typically responds well to suppression of testosterone. Surgical castration is effective in lowering testosterone production but suffers from its psychological impact and irreversibility; thus treatment of the early stages of advanced disease in the Western world is typically based on 'chemical' castration with luteinising hormone releasing hormone (LHRH) agonists. These agents suppress luteinising hormone release and markedly reduce testicular testosterone production. Even with effective surgical or chemical castration, however, some residual androgen production persists (perhaps within tumor cells themselves or from extra-testicular sources); hence there has been a search for other agents to manage the disease.

More recently, AR blockade therapies have been developed, and these agents are now also commonly used to manage prostate cancer. These act by blocking the stimulatory action of testosterone on cells via a direct antagonist action on the AR. In advanced progressive prostate cancer, an LHRH agonist and anti-androgen therapy are frequently combined (often termed 'maximum androgen blockade'). Ultimately, however, advanced prostate cancer becomes resistant to these treatments and progresses, becoming castration-resistant prostate cancer (CRPC) [2]. Still, even at this stage, CRPC seems largely to be driven by the $\mathrm{AR}$, and therapy continuing to target the androgen axis offers promise for delaying further disease progression. A number of agents or therapies targeting the AR axis have recently been shown to provide clinical benefit in trials. In this report we provide a brief overview of the AR, followed by a discussion of new and investigational second generation agents which continue to target the receptor and the androgen axis as treatment of CRPC. It was not our intent, however, to provide an exhaustive review of all anti-androgen therapies.

The AR is a member of a nuclear hormone receptor superfamily that regulates target gene expression [4]. Two AR target genes that have been well characterized include $K L K 3$ regulating prostate specific antigen (PSA) and TMPRSS2-ETS fusion genes; control of these genes includes regulation by the AR, DNA-binding transcription factors and other co-regulatory factors [5-7]. In androgen-dependent prostate cancer, the AR is known to promote cell proliferation through regulation of G1/S transition in the cell cycle, but only in the presence of androgen [8]. In androgen-independent prostate cancer, however, the AR appears to remain active through a variety of potential mechanisms including mutation and amplification of the AR, local production of androgens, increased androgen sensitivity and activation by growth factors [9-11]. In androgen-independent prostate cancer cells, the AR up-regulates M-phase cell cycle genes, including UBE2C, a gene which inactivates the checkpoint of the M-phase; a similar up-regulation was not seen in cells which were androgen-dependent [12]. Histone H3K4 methylation and FoxA1 transcription factor binding appear in androgen-independent cells and drive UBE2C activation. The authors concluded that the AR regulates a distinct transcription program in androgen-independent prostate cancer [12].

During the development of the prostate and prostatic epithelium, effects of androgens are thought to be due to stromal AR [13]. With the transformation of the normal prostate cell to a cancerous one, it is believed that there is a change in AR signaling from a paracrine mechanism to one that is autonomous within the cell $[14,15]$. Intraepithelial neoplastic transformation is a recognized precursor to prostate cancer [16], and such transformation may be initiated, for example, by cell-autonomous AKT activation or by paracrine fibroblast growth factor induction dependent on epithelial AR signaling [17] The AR appears to serve multiple functions, and may serve both to promote proliferation and survival in stromal and epithelial luminal cells, respectively, or to suppress metastasis in epithelial basal cells [18].

Once established, prostate cancer remains dependent on androgen signaling through the AR. The AR is essential for prostate cancer growth both while it is amenable to androgen blockade and after it progresses to CRPC [11]. Although CRPC is often considered as androgen-independent since most cases progress even in the face of castrate levels of testosterone [19], it commonly remains hormone driven $[20,21]$. AR protein is expressed in a great majority of prostate cancer, both in the androgen-dependent and -independent states [19]; reductions of AR protein reduce growth of both in experimental models $[22,23]$. Changes in AR signaling during progression to CRPC are common, and AR is frequently overexpressed in CRPC [22,24,25]. Intratumoral levels of androgens are high with continued activation of the AR in CRPC despite low circulating androgens; tumor cells may independently synthesize androgens de novo [26,27]. CRPC cells with

*Corresponding author: Richard D. Finkelman, AstraZeneca Pharmaceuticals LP 1800 Concord Pike, P.O. Box 15437, Wilmington, DE 19850-5437, USA, Tel: 302 886-1685; Fax: 302-886-2622; E-mail: richard.finkelman@astrazeneca.com

Received January 13, 2012; Accepted January 29, 2012; Published February 01,2012

Citation: Finkelman RD, Clack G (2012) The Androgen Receptor in CastrationResistant Prostate Cancer: Still a Clinical Opportunity? J Cancer Sci Ther S5:e001. doi:10.4172/1948-5956.S5-e001

Copyright: (c) 2012 Finkelman RD, et al. This is an open-access article distributed under the terms of the Creative Commons Attribution License, which permits unrestricted use, distribution, and reproduction in any medium, provided the original author and source are credited. 
high levels of AR may be rendered hypersensitive even to reduced levels of androgens $[28,29]$. Other mechanisms that could keep AR signaling elevated in CRPC include mutations in the AR [30], splice variants [31] or changes in coregulatory proteins [32]. Thus, AR signaling appears to play a critical role in prostate cancer, and the AR is an attractive target for therapy for CRPC. Since the observation of a survival benefit in CRPC with docetaxel in 2004 [33], there has been a keen interest in agents that target the androgen axis for treatment of CRPC. A brief discussion of new and investigational agents in this regard follows below.

\section{Abiraterone}

Abiraterone is a potent and irreversible inhibitor of the enzyme 17 a-hydroxylase/C17,20 lyase (CYP17), the catalyst for the two essential steps of androgen biosynthesis: (1) the conversion of pregnenolone and progesterone to their 17 a-hydroxyderivatives; and (2) the subsequent formation of dehydroepiandrosterone (DHEA) and androstenedione [34], precursors of testosterone. Since CYP17 is expressed in testicular, adrenal and prostatic tissues, it was hypothesized that abiraterone may be effective in CRPC by inhibiting the extragonadal production of androgen that could potentially drive CRPC progression [20].

Abiraterone acetate was tested in a number of Phase I and II studies to evaluate initial safety and tolerability [20,35-39]. In a Phase III trial, 1195 post-docetaxel CRPC patients were randomized 2:1 to study treatment with $5 \mathrm{mg}$ prednisone twice daily and either abiraterone acetate $1000 \mathrm{mg}$ or placebo once daily, respectively [40]. Treatment with abiraterone acetate with prednisone versus placebo with prednisone resulted in a $36 \%$ increase in median survival ( 14.8 vs 10.9 months) and a $35 \%$ reduction in the risk of death (hazard ratio, 0.65 ; $95 \%$ CI, 0.54 to 0.77; $\mathrm{P}<0.001$ ), respectively [40]. Additionally, study treatment versus placebo resulted in an improvement in progression-free survival (5.6 vs 3.6 months; $\mathrm{P}<0.001$ ), time to PSA progression ( 10.2 vs 6.6 months; $\mathrm{P}<0.001)$, and PSA response rate $(29 \%$ vs $6 \% ; \mathrm{P}<0.001)$, respectively. Adverse events reported more frequently in the treated group compared with placebo included fluid retention, hypertension and hypokalemia [40]. On the basis of these Phase III results, abiraterone acetate was initially approved for use in the United States in April, 2011 [41], and subsequently in Europe in September, 2011 [42], in the post-docetaxel setting. Another Phase III study is underway in patients not yet treated with chemotherapy (Clinicaltrials.gov registry number: NCT00887198).

The activity of abiraterone demonstrated that targeting the androgen axis is still an effective treatment strategy for prostate cancer even after it has progressed to a castration-resistant state. Unfortunately, resistance to abiraterone acetate may develop, and a recent preclinical study has suggested that this resistance may develop due to up-regulation of CYP17 or the induction of the AR or variants that promote ligand-independent activation [43]. The appearance of abiraterone resistance suggests the potential for combination therapy with an agent that directly targets the AR as a possible therapeutic strategy to decrease the development of resistance to abiraterone acetate.

\section{MDV3100}

MDV3100 (Medivation, Inc., San Francisco, CA, USA/Astellas Pharma Inc, Tokyo, Japan) is an AR antagonist designed to improve binding affinity and reduce agonist activity compared with available therapies [44]. It has a higher affinity for the AR versus bicalutamide, reduces nuclear translocation, DNA binding and coactivator recruitment and may increase apoptosis; additionally, it appears to be devoid of any agonist activity [44,45]. In a Phase I-II study, 140 patients with metastatic CRPC were enrolled in ascending dose cohorts and treated with doses ranging from 30-600 mg administered once daily (maximum tolerated dose: $240 \mathrm{mg}$ ) [44]. There was preliminary evidence for response to therapy [reduction in PSA of $\geq 50 \%$ (56\% of patients); soft tissue response ( $22 \%$ of patients); stabilized bone disease (56\% of patients); and improvement in circulating tumor cell (CTC) counts ( $49 \%$ of patients)]. On the basis of these encouraging results, a number of Phase II trials and a Phase III registration trial were started.

The Phase III AFFIRM trial of MDV3100 (registry number: NCT00974311) enrolled 1,199 men with advanced prostate cancer who had been previously treated with docetaxel-based chemotherapy. An interim analysis showed that the study had met its pre-specified efficacy stopping criteria, evidencing a significant improvement in overall survival compared with placebo (18.4 vs 13.6 months, respectively; $\mathrm{P}<0.0001$ ), with a $37 \%$ reduction in risk of death (HR: 0.63) [46]. As a result, the study was stopped early by the Independent Data Monitoring Committee, and men randomized to placebo were offered therapy with MDV3100 [46]. A Phase III trial (PREVAIL) is ongoing in men with advanced prostate cancer who have not yet received chemotherapy (registry number: NCT01212991). The ongoing Phase II TERRAIN trial (MDV3100 compared with bicalutamide) is studying men who have progressed while on LHRH analogue therapy or following surgical castration (registry number: NCT01288911). Hormone-naïve patients are currently being studied in a Phase II trial to evaluate MDV3100 monotherapy (registry number: NCT01302041).

\section{TAK-700}

Tak-700 (ortoronel; Millenium Pharmaceuticals, Cambridge, MA, USA/Takeda, Osaka, Japan) is an orally available, selective inhibitor of CYP17. In preliminary results from a Phase II trial of patients with metastatic CRPC, TAK-700 resulted in a dose-dependent decrease in androgen levels and in PSA reductions of at least $50 \%$ in a majority of patients [47]. TAK-700 administered with prednisone is being studied in an ongoing, placebo-controlled, Phase III clinical trial in patients with metastatic CRPC who are naïve to chemotherapy; primary endpoints are overall survival and radiographic progression-free survival (registry number: NCT01193244). A second placebo-controlled Phase III trial of TAK-700 adminstered with prednisone is ongoing in patients with metastatic CRPC who had previously received chemotherapy with docetaxel (registry number: NCT01193257). The primary outcome measure is overall survival.

\section{TOK-001}

TOK-001 (galeterone; Tokai Pharmaceuticals, Cambridge, MA) is an orally available CYP17 inhibitor with additional direct AR antagonist activity $[48,49]$. A Phase I trial (ARMOR1) to evaluate safety (primary objective) and preliminary efficacy (secondary) in patients with CRPC who are chemotherapy-naive is ongoing (registry number: NCT00959959).

\section{ARN-509}

ARN-509 (Aragon Pharmaceuticals, Inc, San Diego, CA, USA) is a novel AR antagonist [50]. It is being studied in an ongoing Phase I/II trial to assess safety and preliminary efficacy in patients with progressive, advanced CRPC (registry number: NCT01171898). The 
Phase II portion of the trial has three arms to assess ARN-509 in (1) non-metastatic, treatment-naive CRPC with rapidly rising PSA; (2) metastatic, treatment-naive CRPC; and (3) post-abiraterone but chemotherapy-naive metastatic CRPC. The primary outcome is PSA response, as the percentage of patients reaching at least a $50 \%$ reduction in PSA compared with baseline at 12 weeks.

\section{AZD3514}

AZD3514 (AstraZeneca, London, United Kingdom) is an orally available, AR down-regulator, therapy which could act on activation of the AR via ligand-independent mechanisms [43,50]. Phase I trials to evaluate safety (primary objective) and preliminary efficacy (secondary) in patients with progressive, metastatic CRPC are ongoing in Europe (registry number: NCT01162395) and Japan (registry number: NCT01351688).

In summary, therapy directed at the androgen axis has been a mainstay of the management of prostate cancer for decades. It is clear that, although the biology of the AR is complex and still evolving, the $\mathrm{AR}$ is a key player in the initiation and progression of prostate cancer and remains as a critical component for the progression of CRPC (for recent reviews, see Ryan and Tindall [49] and Attard et al. [50]). Indeed, the evidence supports that the AR remains a key driver of the disease even after it has progressed and become castration-resistant. Multiple new agents that target the AR or the androgen axis have either become available or are investigational for the treatment of CRPC. Different agents used either in combination or in specific sequence may aid in therapy by combating the resistance that can develop with single agent therapy. Additionally, the development of other endpoints, such as CTC counts, may help to address the challenge posed by the need to meet the regulatory demand for overall survival (OS) data. CTC counts have been reported by a number of investigators to be associated with OS [51-53]. Further clinical trials will be required to address these hypotheses. Our view is that there is real promise for the availability of more tools in the near future for the clinical management of prostate cancer.

\section{Conflict of Interest}

Dr. Finkelman and Dr. Clack are full time employees of AstraZeneca and own stock in AstraZeneca.

\section{References}

1. National Cancer Institute 2011

2. Taichman RS, Loberg RD, Mehra R, Pienta KJ (2007) The evolving biology and treatment of prostate cancer. J Clin Invest 117: 2351-2361.

3. Huggins C, Hodges CV (1941) Studies on prostatic cancer. I. The effect of castration, of estrogen and of androgen injection on serum phosphatases in metastatic carcinoma of the prostate. Cancer Res 1: 293-297.

4. Mangelsdorf DJ, Thummel C, Beato M, Herrlich P, Schütz G, et al. (1995) The nuclear receptor superfamily: The second decade. Cell 83: 835-839.

5. Shang $Y$, Myers M, Brown M (2002) Formation of the androgen receptor transcription complex. Mol Cell 9: 601-610.

6. Wang Q, Carroll JS, Brown M (2005) Spatial and temporal recruitment of androgen receptor and its coactivators involves chromosomal looping and polymerase tracking. Mol Cell 19: 631-642.

7. Wang Q, Li W, Liu XS, Carroll JS, Jänne OA, et al. (2007) A hierarchica network of transcription factors governs androgen receptor-dependent prostate cancer growth. Mol Cell 27: 380-392.
8. Comstock CE, Knudsen KE (2007) The complex role of AR signaling after cytotoxic insult: implications for cell cycle based chemotherapeutics. Cell Cycle 6: 1307-1313.

9. Feldman BJ, Feldman D (2001) The development of androgen-independent prostate cancer. Nature Reviews Cancer 1: $34-45$

10. Heinlein CA, Chang C (2004) Androgen receptor in prostate cancer. Endocrine Reviews 25: 276-308.

11. Debes JD, Tindall DJ (2004) Mechanisms of androgen-refractory prostate cancer. N Engl J Med 351: 1488-1490.

12. Wang Q, Li W, Zhang Y, Yuan X, Xu K, et al. (2009) Androgen recepto regulates a distinct transcription program in androgen-independent prostate cancer. Cell 138: 245-256.

13. Cunha GR (2008) Mesenchymal-epithelial interactions: past, present, and future. Differentiation 76: 578-586.

14. Gao J, Arnold JT, Isaacs JT (2001) Conversion from a paracrine to an autocrine mechanism of androgen-stimulated growth during malignant transformation of prostatic epithelial cells. Cancer Res 61: 5038-5044.

15. Vander Griend DJ, D’Antonio J, Gurel B, Antony L, Demarzo AM, et al. (2010) Cell-autonomous intracellular androgen receptor signaling drives the growth of human prostate cancer initiating cells. Prostate 70: 90-99.

16. Abate-Shen C, Shen MM (2000) Molecular genetics of prostate cancer. Genes \& Dev 14: 2410-2434.

17. Memarzadeh S, Cai J, Janzen DM, Xin L, Lukacs R, et al. (2011) Role of autonomous androgen receptor signaling in prostate cancer initiation is dichotomous and depends on the oncogenic signal. Proc Natl Acad Sci USA 108: 7962-7967

18. Niu Y, Altuwaijri S, Lai KP, Wu CT, Ricke WA, et al. (2008) Androgen receptor is a tumor suppressor and proliferator in prostate cancer. Proc Natl Acad Sc USA 105: 12182-12187.

19. Scher HI, Sawyers CL (2005) Biology of progressive, castration-resistan prostate cancer: Directed therapies targeting the androgen-receptor signaling axis. J Clin Oncol 23: 8253-8261.

20. Attard G, Reid AH, Yap TA, Raynaud F, Dowsett M, et al. (2008) Phase clinical trial of a selective inhibitor of CYP17, abiraterone acetate, confirms that castration-resistant prostate cancer commonly remains hormone driven. J Clin Oncol 26: 4563-4571.

21. Ang JE, OImos D, de Bono JS (2009) CYP17 blockade by abiraterone: furthe evidence for frequent continued hormone-dependence in castration-resistan prostate cancer. Br J Cancer 100: 671-675.

22. Chen CD, Welsbie DS, Tran C, Baek SH, Chen R, et al. (2004) Molecula determinants of resistance to antiandrogen therapy. Nature Med 10: 33-39.

23. Haag P, Bektic J, Bartsch G, Klocker H, Eder IE (2005) Androgen recepto down regulation by small interference RNA induces cell growth inhibition in androgen sensitive as well as in androgen independent prostate cancer cells. J Steroid Biochem Mol Biol 96: 251-258.

24. Linja MJ, Savinainen KJ, Saramäki OR, Tammela TL, Vessella RL, et al. (2001) Amplification and overexpression of androgen receptor gene in hormonerefractory prostate cancer. Cancer Res 61: 3550-3555.

25. Holzbeierlein J, Lal P, LaTulippe E, Smith A, Satagopan J, et al. (2004) Gene expression analysis of human prostate carcinoma during hormonal therapy identifies androgen-responsive genes and mechanisms of therapy resistance. Am J Pathol 164: 217-227.

26. Locke JA, Guns ES, Lubik AA, Adomat HH, Hendy SC, et al. (2008) Androgen levels increase by intratumoral de novo steroidogenesis during progression of castration-resistant prostate cancer. Cancer Res 68: 6407-6415.

27. Montgomery RB, Mostaghel EA, Vessella R, Hess DL, Kalhorn TF, et al. (2008) Maintenance of intratumoral androgens in metastatic prostate cancer: A mechanism for castration-resistant tumor growth. Cancer Res 68: 4447-4454.

28. Waltering KK, Helenius MA, Sahu B, Manni V, Linja MJ, et al. (2009) Increased expression of androgen receptor sensitizes prostate cancer cells to low levels of androgens. Cancer Res 69: 8141-8149. 
Citation: Finkelman RD, Clack G (2012) The Androgen Receptor in Castration-Resistant Prostate Cancer: Still a Clinical Opportunity? J Cancer Sci Ther S5:e001. doi:10.4172/1948-5956.S5-e001

Page 4 of 4

29. Kawata H, Ishikura N, Watanabe M, Nishimoto A, Tsunenari $T$, et al (2010) Prolonged treatment with bicalutamide induces androgen receptor overexpression and androgen hypersensitivity. Prostate 70: 745-754.

30. Taplin ME, Rajeshkumar B, Halabi S, Werner CP, Woda BA, et al. (2003) Androgen receptor mutations in androgen-independent prostate cancer: Cancer and Leukemia Group B Study 9663. J Clin Oncol 21: 2673-2678.

31. Sun S, Sprenger CC, Vessella RL, Haugk K, Soriano K, et al. (2010) Castration resistance in human prostate cancer is conferred by a frequently occurring androgen receptor splice variant. J Clin Invest 120: 2715-2730.

32. Urbanucci A, Waltering KK, Suikki HE, Helenius MA, Visakorpi T (2008) Androgen regulation of the androgen receptor coregulators. BMC Cancer 8 : 219.

33. Tannock IF, de Wit R, Berry WR, Horti J, Pluzanska A, et al. (2004) Docetaxel plus prednisone or mitoxantrone plus prednisone for advanced prostate cancer. N Engl J Med 351: 1502-1512.

34. Attard G, Belldegrun AS, de Bono JS (2005) Selective blockade of androgenic steroid synthesis by novel lyase inhibitors as a therapeutic strategy for treating metastatic prostate cancer. BJU Int 96: 1241-1246.

35. Attard G, Reid AH, A'Hern R, Parker C, Oommen NB, et al. (2009) Selective inhibition of CYP17 with abiraterone acetate is highly active in the treatment of castration-resistant prostate cancer. J Clin Oncol 27: 3742-3748.

36. Ryan CJ, Smith MR, Fong L, Rosenberg JE, Kantoff P, et al. (2010) Phase clinical trial of the CYP17 inhibitor abiraterone acetate demonstrating clinical activity in patients with castration-resistant prostate cancer who received prior ketoconazole therapy. J Clin Oncol 28: 1481-1488.

37. Danila DC, Morris MJ, de Bono JS, Ryan CJ, Denmeade SR, et al. (2010) Phase II multicenter study of abiraterone acetate plus prednisone therapy in patients with docetaxel-treated castration-resistant prostate cancer. J Clin Oncol 28: 1496-1501

38. Reid AH, Attard G, Danila DC, Oommen NB, Olmos D, et al. (2010) Significan and sustained antitumor activity in post-docetaxel, castration-resistant prostate cancer with the CYP17 inhibitor abiraterone acetate. J Clin Oncol 28: 14891495.

39. Ryan CJ, Shah S, Efstathiou E, Smith MR, Taplin ME, et al. (2011) Phase II study of abiraterone acetate in chemotherapy-naïve metastatic castrationresistant prostate cancer displaying bone flare discordant with serologic response. Clin Cancer Res 17: 4854-4861.

40. de Bono JS, Logothetis CJ, Molina A, Fizazi K, North S, et al. (2011) Abiraterone and increased survival in metastatic prostate cancer. N Engl J Med 364: 19952005

41. Zytiga [package insert]. Centocor Ortho Biotech Inc., Horsham, PA, April 2011

42. Zytiga [package leaflet]. Janssen-Cilag International NV, Beerse, Belgium, September 2011

43. Mostaghel EA, Marck BT, Plymate SR, Vessella RL, Balk S, et al. (2011) Resistance to CYP17A1 inhibition with abiraterone in castration-resistan prostate cancer: induction of steroidogenesis and androgen receptor splice variants. Clin Cancer Res 17: 5913-5925.

44. Scher HI, Beer TM, Higano CS, Anand A, Taplin ME, et al. (2010) Antitumou activity of MDV3100 in castration-resistant prostate cancer: a phase 1-2 study. Lancet 375: 1437-1446.

45. Chen Y, Clegg NJ, Scher HI (2009) Anti-androgens and androgen-depleting therapies in prostate cancer: new agents for an established target. Lance Oncol 10: 981-991.

46. Press release, Medivation, Inc., San Francisco, CA, USA., 3 November 2011

47. Agus DB (2011) Safety, efficacy, and pharmacodynamics of the investigationa agent TAK-700 in metastatic castration-resistant prostate cancer (mCRPC) Updated data from a phase I/II study. Proceedings of the 2011 Annual Meeting of the American Society of Clinical Oncology.

48. Wu Y, Rosenberg JE, Taplin ME (2011) Novel agents and new therapeutics in castration-resistant prostate cancer. Curr Opin Oncol 23: 290-296.

49. Ryan CJ, Tindall DJ (2011) Androgen receptor rediscovered: The new biology and targeting the androgen receptor therapeutically. J Clin Oncol 29: 3651 . 3658

50. Attard G, Richards J, de Bono JS (2011) New strategies in metastatic prostate cancer: Targeting the androgen receptor signaling pathway. Clin Cancer Res 17: 1649-1657.

51. de Bono JS, Scher HI, Montgomery RB, Parker C, Miller MC, et al. (2008) Circulating tumor cells predict survival benefit from treatment in metastatic castration-resistant prostate cancer. Clin Cancer Res 14: 6302-6309.

52. Olmos D, Arkenau HT, Ang JE, Ledaki I, Attard G, et al. (2009) Circulating tumour cell (CTC) counts as intermediate end points in castration-resistant prostate cancer (CRPC): a single-centre experience. Ann Oncol 20: 27-33.

53. Scher HI, Jia X, de Bono JS, Fleisher M, Pienta KJ, et al. (2009) Circulating tumour cells as prognostic markers in progressive, castration-resistant prostate cancer: a reanalysis of IMMC38 trial data. Lancet Oncol 10: 233-239.
This article was originally published in a special issue, Cancer Research: Clinical \& Experimental handled by Editor(s). Dr. Richard D. Finkelman, AstraZeneca Pharmaceuticals LP, USA; Dr. Jimmy Thomas Efird, University of North Carolina, USA; Dr. Yanming Wang, Case Western Reserve University, USA 